\title{
Comparative Analysis of Carbon Monoxide Modeling from Vehicular Sources in Puebla City, México
}

\author{
Sthephany Sedeño-Cisneros' ${ }^{1}$ María Auxilio Osorio-Lama1, Miguel Ángel Valera-Pérez², \\ René Bernardo Elías Cabrera-Cruz ${ }^{3}$ \\ ${ }^{1}$ Faculty of Chemical Engineering Praiseworthy, Autonomous University of Puebla, Puebla, México \\ ${ }^{2}$ Institute of Sciences, Praiseworthy Autonomous University of Puebla, Puebla, México \\ ${ }^{3}$ Faculty of Engineering "Arturo Narro Siller", Autonomous University of Tamaulipas, Tampico, México \\ Email: valeraperezmiguelangel@gmail.com, rcabreracruz@uat.edu.mx
}

Received 5 January 2015; accepted 25 January 2015; published 28 January 2015

Copyright (C) 2014 by authors and Scientific Research Publishing Inc.

This work is licensed under the Creative Commons Attribution International License (CC BY).

http://creativecommons.org/licenses/by/4.0/

c) (i) Open Access

\begin{abstract}
The results of dispersion modeling of carbon monoxide are reported in this paper. The results of applying the technique of Rapid Assessment of Sources of Environmental Pollution (RASEP) database and the Air Monitoring State System in the City of Puebla, México, were employed. Concentrations of carbon monoxide emitted by cars inferred by RASAP technique with those reported by the environmental monitoring station "Nymphs", were compared. The date of 21 June 2005-2010 was selected during the peak hour traffic flow. The dispersion of carbon monoxide was modeled by software DISPER and SCRI software, in order to infer the exposure levels of carbon monoxide in the study area. The estimated and monitored concentrations were evaluated with the Mexican regulations for population's health protection. Regarding the dispersion model, SCRI was discarded for the target validation because it only allows modeling on specific areas. Moreover, the modeling software allowed DISPER simulations with linear sources of car exhaust, so this advantage is considered appropriate to continue using this program. Both estimates obtained by RASEP, as modeled by DISPER and recorded by the monitoring system exceed the maximum permissible limits of NOM-021-SSA1-1993 getting an impermissible for the area of influence of the assessment monitoring station. The DISPER software has potential use for such evaluations, but more work is required on the system for their inferences can be validated by reproducible physical and chemical measurements.
\end{abstract}

\section{Keywords}

Environmental Pollutants Assessment, Carbon Monoxide, Puebla 


\section{Introduction}

One of the current problems of megacities is the dispersion of large concentrations of toxic substances in the atmosphere, this being a very complex system where countless reactions occur simultaneously, it is essential to assess the potential impact on air quality have those substances. Not only is it important to assess the concentrations of dispersed toxic substances, but also their dispersal mechanisms and eventually the implications for the population exposed to these pollutants [1] occurs. Therefore, environmental modeling, applied to changes in air quality, it is a must, as it relates Miriam Zuk et al. "In this sense, air quality models are a valuable tool, and that in formulating the most recent knowledge on atmospheric dynamics are incorporated to model, with some degree of confidence, dispersal patterns, chemical transformation and removal of pollutants, so that an estimate of its concentration in the atmosphere is obtained" [2].

The problem lies in the use of models for environmental management, not always have the database necessary to validate them [3]. An environmental model is a mathematical representation and spatio-temporal phenomena of mass transfer, energy and movement and population dynamics that occur in a system. Is generated in order to facilitate understanding, enable prediction and simulations of their behavior in different physical, chemical or biological conditions [4]. So the answer: why is required to model the environment? tells us that we need to know and predict changing weather conditions and the dynamics of the dispersion of pollutants, to construct scenarios of environmental quality and sustainable development that support strategic decisions in the sectors of society and government level [5]. Building a well-designed model requires examining the elements of the system, processes and structures that govern the relationships and interactions between them and the spatial and temporal components over which processes [6] operate. However, in Mexico used indiscriminately commercially models are provided in the form of software, regardless of how much is that they do not fit or reality and thus decision-making on environmental management that promotes usually are even completely erroneous [7]. Consequently, it is necessary to evaluate and analyze whether environmental modeling software can adapt to different physical models of the study, in order to determine its functionality and reliability for decision making on environmental pollutants assessment and risk analysis [8].

\section{Methodology}

The environment for environmental monitoring station called "Nymphs" located between the formed quadrangle between Avenues 23 west, 25 west, 15 south and 17 south (Figure 1), in a public park was considered the study area center of the city of Puebla [9] [10]. Land use around the park is residential and commercial area. At this high school is located. The streets around the park are moderate traffic, movement of private cars and passenger vehicles.

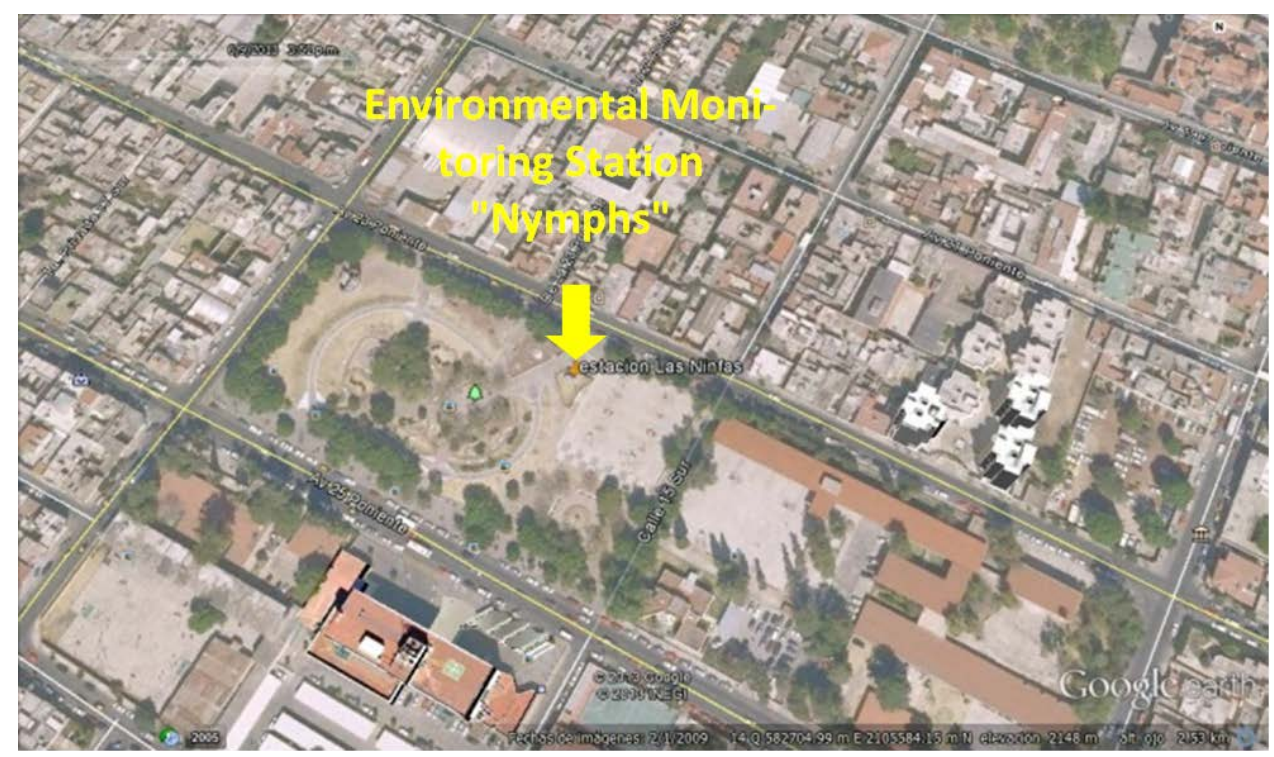

Figure 1. Location of the study area. Note = image more defined. 
The selected parameter for this study was the carbon monoxide (CO), because if the half-life ranges from 1 to 2 months [11] is rapidly oxidized when in contact with the atmosphere being transformed into carbon dioxide, which makes it unlikely that these emissions farthest measurement site mobile sources are recorded. The fact that reports 4th Almanac Data and Trends of Air Quality in 20 Mexican cities [12] [13], which shows that CO emissions are more than 90\% generated by the vehicle fleet was also considered (Figure 2) [14].

It was inferred by RASEP [15] technique, the concentration of CO during peak hour vehicular circulation on 21 June from 2005 to 2010, because it is the longest day of the year and therefore greater exposure atmospheric contaminants to solar radiation, which means a factor for increased dispersion, which was considered as representative of the summer weather conditions. Data required by the SCRI and DISPER software were introduced; to perform modeling $\mathrm{CO}$ emissions. The validation of the results of the modeling was performed by comparing CO concentrations reported by the models in the area of environmental monitoring station "Nymphs" with measurements made by the censors of the station and reported in database provided by the State Air Monitoring System in the City of Puebla.

\section{Results and Discussion}

During the modeling conducted for the SCRI software, a major problem that led to rule out such a program for the target validation was found. This problem lies in the options allowed by the software issue because for the purposes of this modeling, it is necessary to consider a CO line and SCRI modeling software allows only very small areas or specific issues without the ability to change the position and conditions of each of them (Figure 3).

In Figure 3, one of the images obtained in the simulation is presented. In it two point sources corresponding to the location of the streets 25 and 23 are observed setting. Moreover, the software also uses modeling DISPER the Gaussian model used in the SCRI and also allows simulations with linear sources of car exhaust (Figure 4), so that this advantage was considered appropriate to use this program.

Table 1 shows some of the variables considered in the modeling with software DISPER the years indicated in the methodology are listed. Note $=$ Table 1 and Table 2 made them into real tables.

The results of the modeling performed are listed in the table.

Given the results, one can notice a considerable margin between the concentrations in both modeling, however this is consistent whereas modeling are different (line and point source transmitter). The modeling software with SCRI does not describe the way how are the sources of emissions or pollutants dispersed according to the actual physical structure of the system, so that its use for the purposes of this work was discarded.

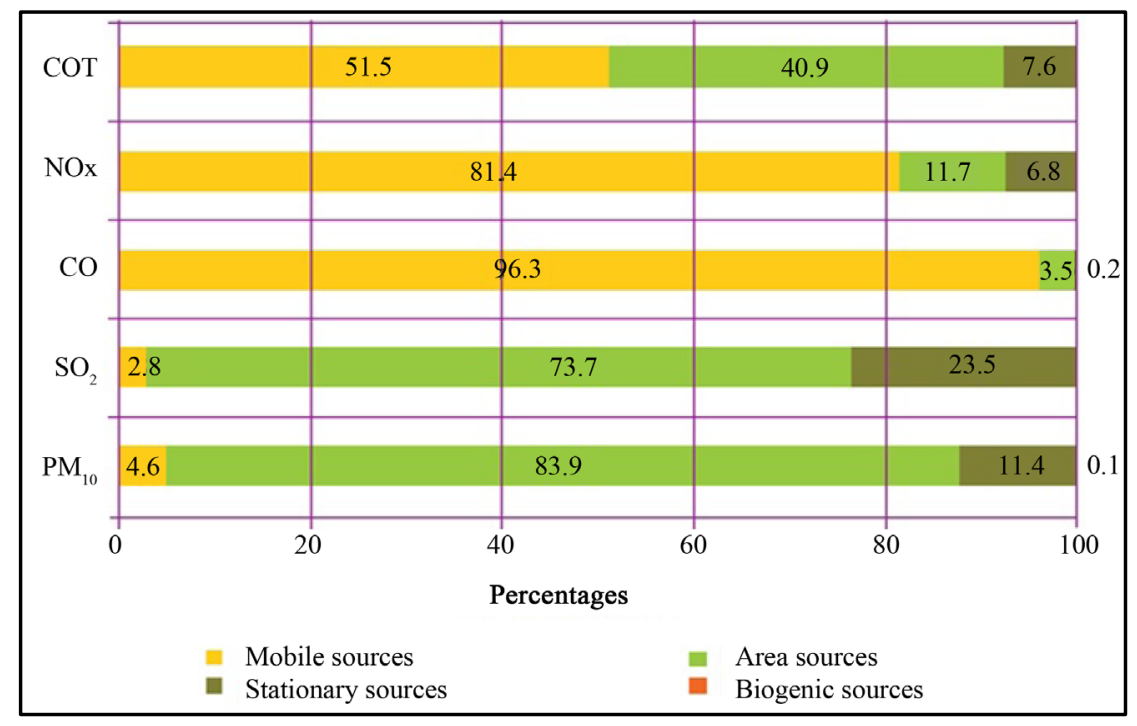

Figure 2. Emissions Inventory Puebla (2004), it is observed that motor vehicles provide the most significant $\mathrm{CO}$ emissions. Note: $\mathrm{CO}=$ Carbon Monoxide; $\mathrm{SO}_{2}=$ Sulfur Dioxide; $\mathrm{NO}_{\mathrm{x}}=$ Nitrogen Oxides; $\mathrm{PM}_{10}=$ Particulate Material 10; COT = Total Organic Carbon for its acronym in Spanish. 


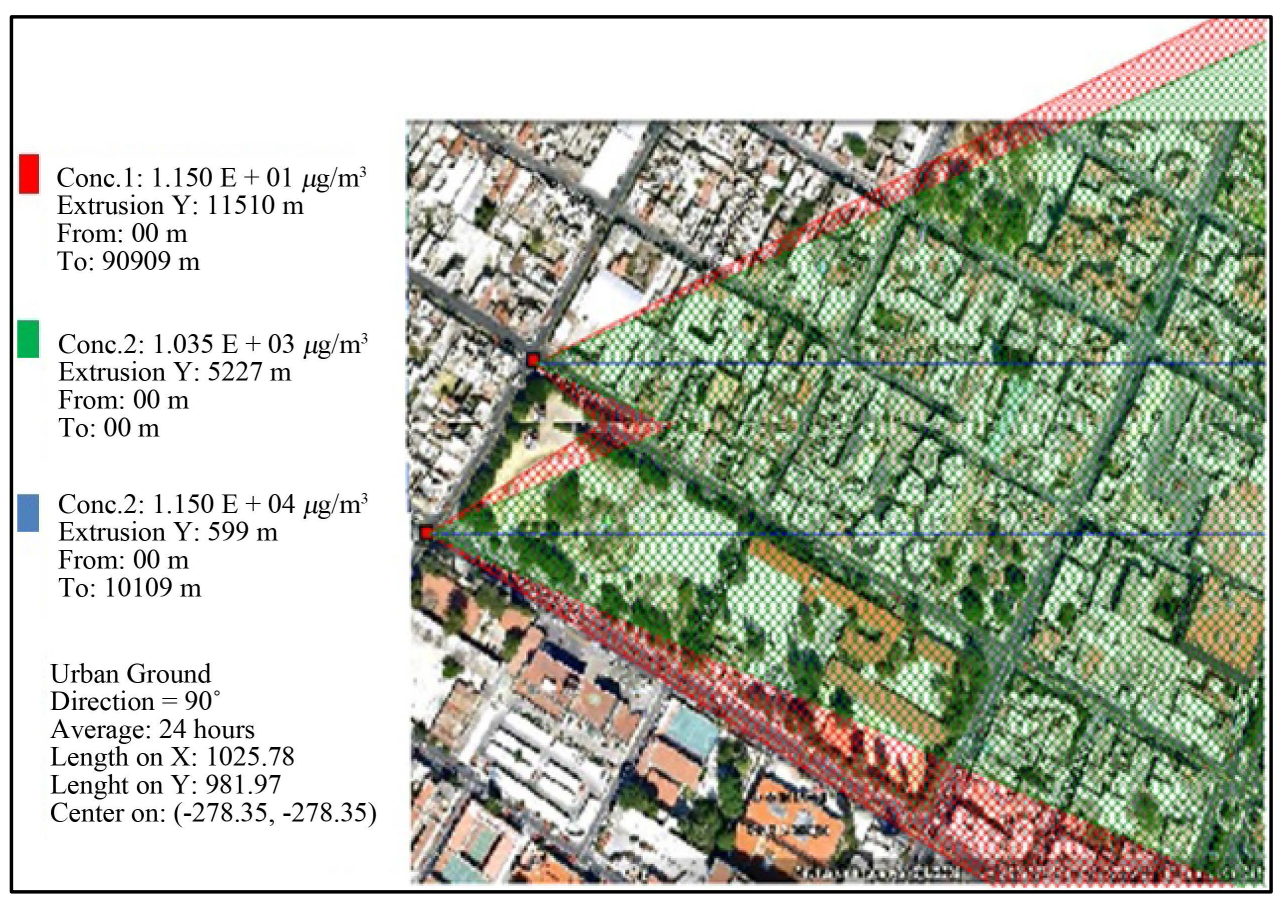

Figure 3. Simulation of dispersion of CO with SCRI software.

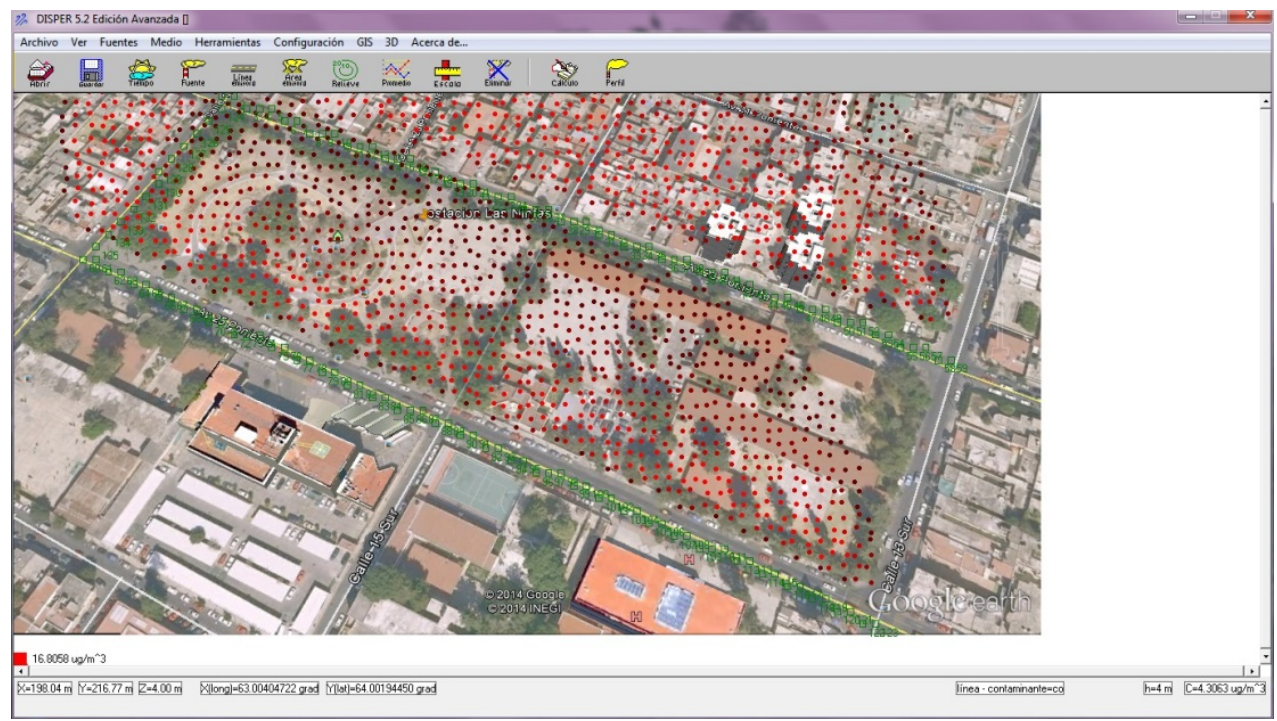

Figure 4. Modeling of line sources on the software DISPER 2005.

The results obtained by modeling the software DISPER best describe the physical system to consider a line of mobile source emissions (Figure 5), however, the values of the concentration of CO inferred for the point where the censors environmental monitoring station are higher measured and reported to the State database Atmospheric Monitoring System in the city of Puebla, which in principle establishes it is no validation. This means that there are some factors that are present in the physical phenomenon but have not been considered by the software, so it requires a mathematical work of numerical methods to modify and improve inferences [16].

Given the results, one can notice a considerable margin between the concentrations in both modeling, however, this is consistent whereas modeling are different (line and point source transmitter). The modeling software with SCRI not describes the way how are the sources of emissions or pollutants dispersed according to the actual physical structure of the system, so that its use for the purposes of this work was discarded. 
Table 1. Variables considered for modeling and their magnitudes. Data are for the years 2001, 2002, 2003, 2004,2005 and 2007, correspondingly.

\begin{tabular}{|c|c|c|c|c|c|c|c|c|c|c|}
\hline 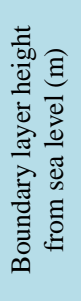 & 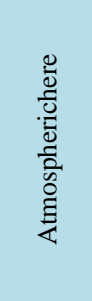 & 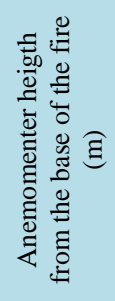 & 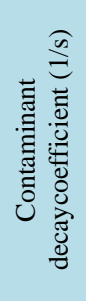 & 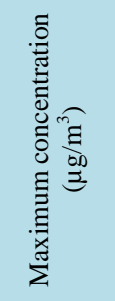 & 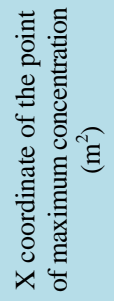 & 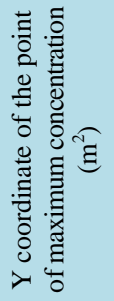 & 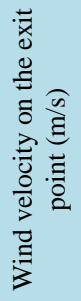 & 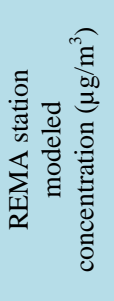 & 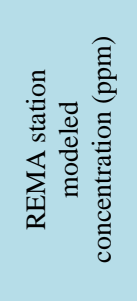 & 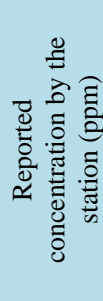 \\
\hline 2160 & Urban & 4 & 0 & 17.656 & 18.49 & 195.56 & 35.3 & 6.073 & 7073.844 & 2.87 \\
\hline 2160 & Urban & 4 & 0 & 63.089 & 24.65 & 201.72 & 35.3 & 10.544 & 12280.399 & 2.87 \\
\hline 2160 & Urban & 4 & 0 & 77.996 & 24.65 & 201.72 & 35.3 & 10.947 & 12750.250 & 2.87 \\
\hline 2160 & Urban & 4 & 0 & 101.485 & 18.49 & 220.21 & 7 & 2.853 & 3322.496 & 1.43 \\
\hline 2160 & Urban & 4 & 0 & 258.229 & 24.65 & 214.05 & 7 & 2.887 & 3362.795 & 1.43 \\
\hline 2160 & Urban & 4 & 0 & & & & & 2.890 & 3365.474 & 1.43 \\
\hline 2160 & Urban & 4 & 0 & 16.806 & 67.79 & 275.68 & 20 & 4.306 & 5015.657 & 2.62 \\
\hline 2160 & Urban & 4 & 0 & 120.495 & 67.79 & 257.19 & 20 & 4.488 & 5227.404 & 2.62 \\
\hline 2160 & Urban & 4 & 0 & 204.044 & 67.79 & 257.19 & 20 & 4.501 & 5241.847 & 2.62 \\
\hline 2160 & Urban & 4 & 0 & 270.939 & 104.77 & 300.33 & 1.6 & 36.847 & 42916.290 & 2.26 \\
\hline 2160 & Urban & 4 & 0 & 617.390 & 73.96 & 263.35 & 1.6 & 37.771 & 43993.078 & 2.26 \\
\hline 2160 & Urban & 4 & 0 & 720.464 & 73.96 & 263.35 & 1.6 & 37.834 & 44065.874 & 2.26 \\
\hline 2160 & Urban & 4 & 0 & 145.863 & 86.28 & 288.01 & 3.7 & 41.911 & 48814.692 & 1.06 \\
\hline 2160 & Urban & 4 & 0 & 511.461 & 135.59 & 269.52 & 3.7 & 43.555 & 50729.035 & 1.06 \\
\hline 2160 & Urban & 4 & 0 & 633.166 & 135.59 & 269.52 & 3.7 & 43.669 & 50862.280 & 1.06 \\
\hline 2160 & Urban & 4 & 0 & 65.789 & 24.65 & 195.56 & 8.9 & 21.448 & 24980.682 & 1.88 \\
\hline 2160 & Urban & 4 & 0 & 200.321 & 30.82 & 201.72 & 8.9 & 43.078 & 50174.509 & 1.88 \\
\hline 2160 & Urban & 4 & 0 & 242.139 & 30.82 & 201.72 & 8.9 & 45.148 & 52585.025 & 1.88 \\
\hline
\end{tabular}

Table 2. Results of the modeling performed with the software DISPER.

\begin{tabular}{|c|c|c|c|c|c|c|c|c|c|}
\hline 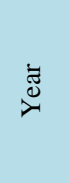 & 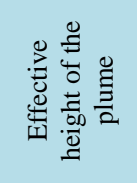 & 오 & 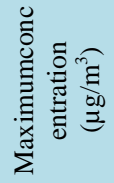 & 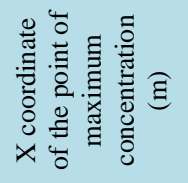 & 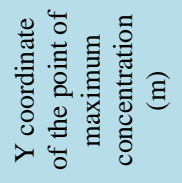 & 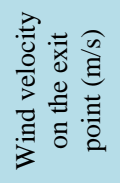 & 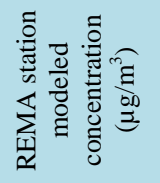 & 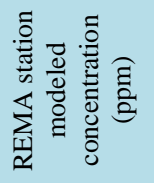 & 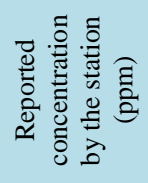 \\
\hline \multirow{3}{*}{2001} & $4 \mathrm{~m}$ & 19 & 17.656 & 18.49 & 195.56 & 35.3 & 6.073 & 7073.844 & 2.87 \\
\hline & $1 \mathrm{~m}$ & 19 & 63.089 & 24.65 & 201.72 & 35.3 & 10.544 & 12280.399 & 2.87 \\
\hline & Floor level & 19 & 77.996 & 24.65 & 201.72 & 35.3 & 10.947 & 12750.250 & 2.87 \\
\hline \multirow{3}{*}{2002} & $4 \mathrm{~m}$ & 8 & 101.485 & 18.49 & 220.21 & 7 & 2.853 & 3322.496 & 1.43 \\
\hline & $1 \mathrm{~m}$ & 8 & 258.229 & 24.65 & 214.05 & 7 & 2.887 & 3362.795 & 1.43 \\
\hline & Floor level & 8 & & & & & 2.890 & 3365.474 & 1.43 \\
\hline \multirow{3}{*}{2003} & $4 \mathrm{~m}$ & 22 & 16.806 & 67.79 & 275.68 & 20 & 4.306 & 5015.657 & 2.62 \\
\hline & $1 \mathrm{~m}$ & 22 & 120.495 & 67.79 & 257.19 & 20 & 4.488 & 5227.404 & 2.62 \\
\hline & Floor level & 22 & 204.044 & 67.79 & 257.19 & 20 & 4.501 & 5241.847 & 2.62 \\
\hline \multirow{3}{*}{2004} & $4 \mathrm{~m}$ & 8 & 270.939 & 104.77 & 300.33 & 1.6 & 36.847 & 42916.290 & 2.26 \\
\hline & $1 \mathrm{~m}$ & 8 & 617.390 & 73.96 & 263.35 & 1.6 & 37.771 & 43993.078 & 2.26 \\
\hline & Floor level & 8 & 720.464 & 73.96 & 263.35 & 1.6 & 37.834 & 44065.874 & 2.26 \\
\hline \multirow{3}{*}{2005} & $4 \mathrm{~m}$ & 12 & 145.863 & 86.28 & 288.01 & 3.7 & 41.911 & 48814.692 & 1.06 \\
\hline & $1 \mathrm{~m}$ & 12 & 511.461 & 135.59 & 269.52 & 3.7 & 43.555 & 50729.035 & 1.06 \\
\hline & Floor level & 12 & 633.166 & 135.59 & 269.52 & 3.7 & 43.669 & 50862.280 & 1.06 \\
\hline \multirow{3}{*}{2007} & $4 \mathrm{~m}$ & 8 & 65.789 & 24.65 & 195.56 & 8.9 & 21.448 & 24980.682 & 1.88 \\
\hline & $1 \mathrm{~m}$ & 8 & 200.321 & 30.82 & 201.72 & 8.9 & 43.078 & 50174.509 & 1.88 \\
\hline & Floor level & 8 & 242.139 & 30.82 & 201.72 & 8.9 & 45.148 & 52585.025 & 1.88 \\
\hline
\end{tabular}




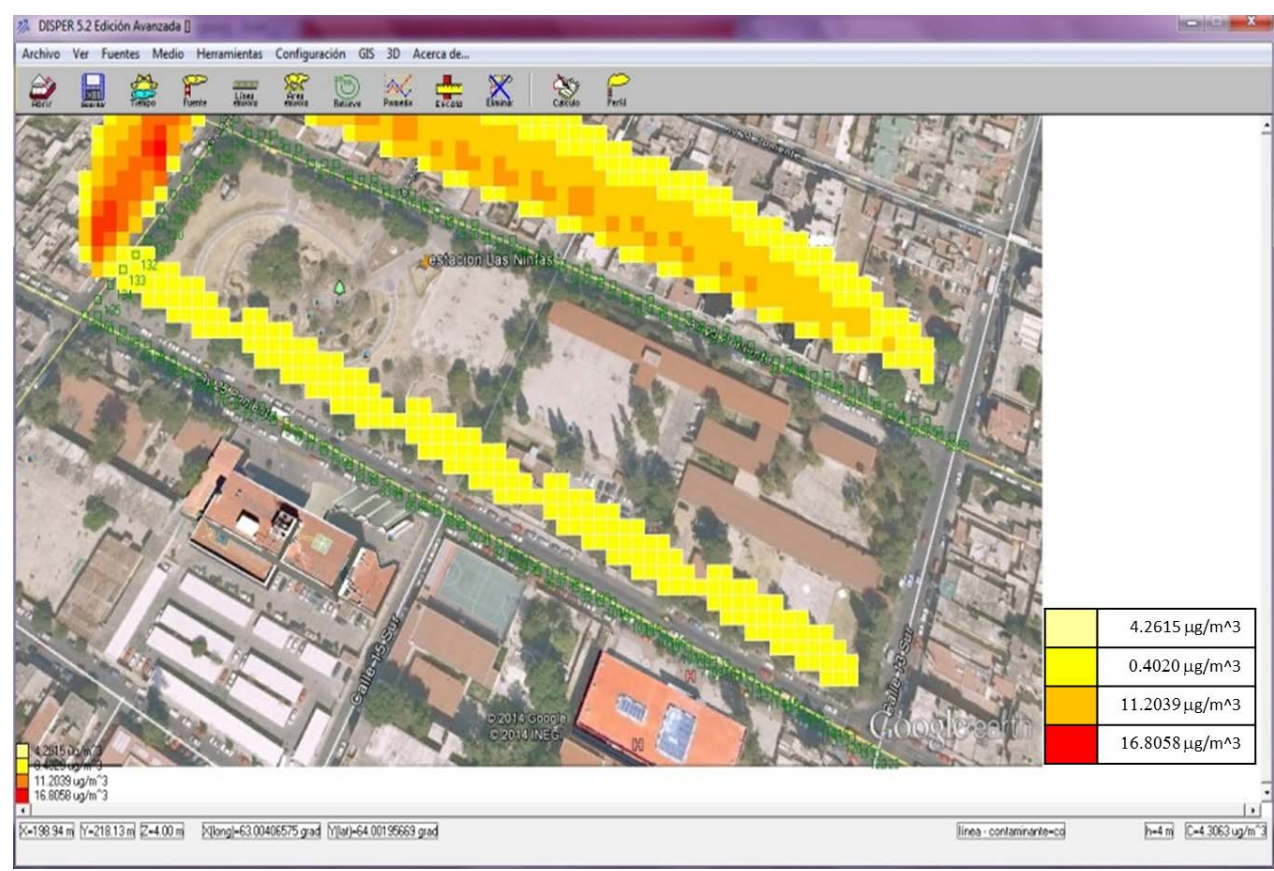

Figure 5. Dispersion modeling of CO for 2003.

The results obtained by modeling the software DISPER best describe the physical system to consider a line of mobile source emissions, however the values of the concentration of CO inferred for the point where the censors environmental monitoring station are higher measured and reported to the State database Atmospheric Monitoring System in the city of Puebla, which in principle establishes it is no validation. This means that there are some factors that are present in the physical phenomenon but have not been considered by the software, so it requires a mathematical work of numerical methods to modify and improve inferences.

\section{Conclusion}

The SCRI presents difficulties in modeling software system for mobile emission sources, so it was left to consider its use for this work. The modeling software allowed DISPER more attachment to the physical system of mobile emission sources, but it was not possible to validate the results of the inferred concentrations with those reported by Station State Atmospheric Monitoring System in the City of Puebla. This includes their potential use for this type of environmental assessments, but more work is required on the system for their inferences can be validated by reproducible physical and chemical measurements.

\section{References}

[1] Al-Jeelani, H.A. (2013) The Impact of Traffic Emission on Air Quality in an Urban Environment. Journal of Environmental Protection, 4, 205-217. http://dx.doi.org/10.4236/jep.2013.42025

[2] Zuk, M., Garivay Bravo, V., Iniestra, R., López, M.T., Rojas Bracho, L. and Laguna, I. (2006) Introduction to impact assessment of thermal power of Mexico. In: Primera, Ed., National Institute of Ecology and Climate Change, México, $117 \mathrm{p}$.

[3] Ebel, A., Melas, D., Ganev, K., Banja, M., Sandu, I., Friese, E., Giannaros, T., Jakobs, H.J., Kioutsioukis, I., Markakis, K., Memmesheimer, M., Miloshev, N., Pescaru, V. and Poupkou, A. (2012) Assessment of Impacts and Risks of Air Pollution Applying Two Strategies of Numerical Chemistry Transport Modelling. Journal of Environmental Protection, 3, 26-40. http://dx.doi.org/10.4236/jep.2012.31004

[4] Barnsley, M.J. (2007) Environmental Modeling. A Practical Approach. CRC Press, Boca Raton.

[5] Balogun, I.A., Balogun, A.A. and Adegoke, J. (2014) Carbon Monoxide Concentration Monitoring in Akure-A Comparison between Urban and Rural Environment. Journal of Environmental Protection, 5, 266-273. http://dx.doi.org/10.4236/jep.2014.54030

[6] Capilla, C. (2012) Application of Statistical Methods to Assess Carbon Monoxide Pollution Variations within an Urban 
Area. International Journal of Geosciences, 3, 885-890. http://dx.doi.org/10.4236/ijg.2012.325090

[7] Cruz-Campas, M.E., Gómez-Álvarez, A., Quintero-Núñez, M., Ramírez-Leal, R., Varela-Salazar, J. and Monge-Amaya, O. (2014) Air Quality Regarding to TSP in Six Cities of Sonora, Mexico, a Criticism to the NOM-025-SSA1-1993 and a Proposed Criterion for Its Non-Compliance. Journal of Environmental Protection, 5, 862-873. http://dx.doi.org/10.4236/jep.2014.510088

[8] An, X.Q., Sun, Z.B., Lin, W.L., Jin, M. and Li, N. (2013) Emission Inventory Evaluation Using Observations of Regional Atmospheric Background Stations of China. Journal of Environmental Sciences, 25, 537-546. http://dx.doi.org/10.1016/S1001-0742(12)60082-5

[9] Directorate of Research and Monitoring Atmospheric Pollutant Analytical Characterization (2013) National Institute of Ecology and Climate Change. http://sinaica.ine.gob.mx/rama_puebla.html

[10] National Institute of Ecology and Climate Change (2012) First Catalog of Monitoring Stations in Mexico. INECC, México. http://www2.inecc.gob.mx/publicaciones/libros/681/cap2.pdf

[11] Teitelbaum, D. (2009) Introduction to Occupational and Environmental Toxicology. 11th Edition, McGraw-Hill-Lange, México.

[12] National Institute of Ecology and Climate Change (2011) Fourth Almanac Data and Trends in Air Quality in 20 Mexican Cities (2000-2009). National Institute of Ecology and Climate Change, México.

[13] National Institute of Ecology and Climate Change (2009) INECC. http://www.inecc.gob.mx/calaire-informacion-basica/537-calaire-fuentes

[14] National Institute of Ecology and Climate Change (2002) Technical Manual of Vehicle Inspection. Secretary of Environment and Natural Resources INECC-SEMARNAT, México.

[15] Weitzenfeld, H. (1989) Rapid Assessment of Sources of Environmental Pollution (Air, Water and Soil). ECO-SEDUE, Metepec.

[16] Rodríguez Martínez, G. (2013) Development of a Predictive Model of Nonreactive Pollutant Dispersion Emitted by Point Sources. Master Thesis, Praiseworthy Autonomous University of Puebla, Puebla, 105 p. 
Scientific Research Publishing (SCIRP) is one of the largest Open Access journal publishers. It is currently publishing more than 200 open access, online, peer-reviewed journals covering a wide range of academic disciplines. SCIRP serves the worldwide academic communities and contributes to the progress and application of science with its publication.

Other selected journals from SCIRP are listed as below. Submit your manuscript to us via either submit@scirp.org or Online Submission Portal.
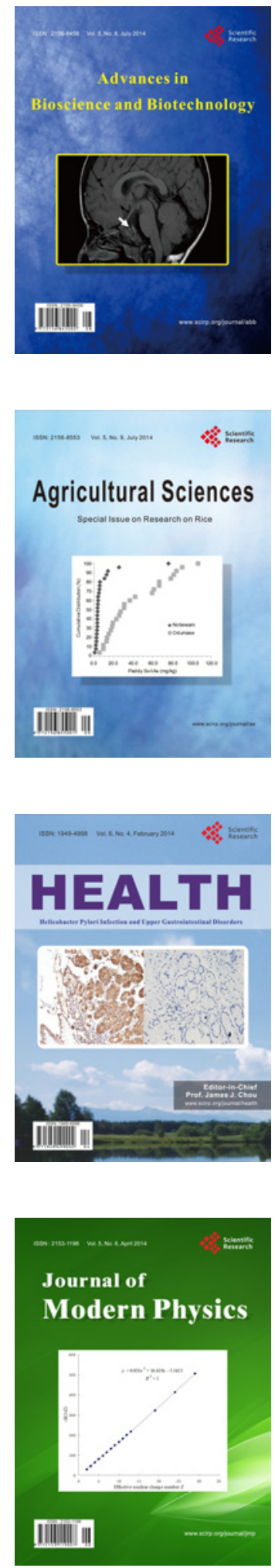
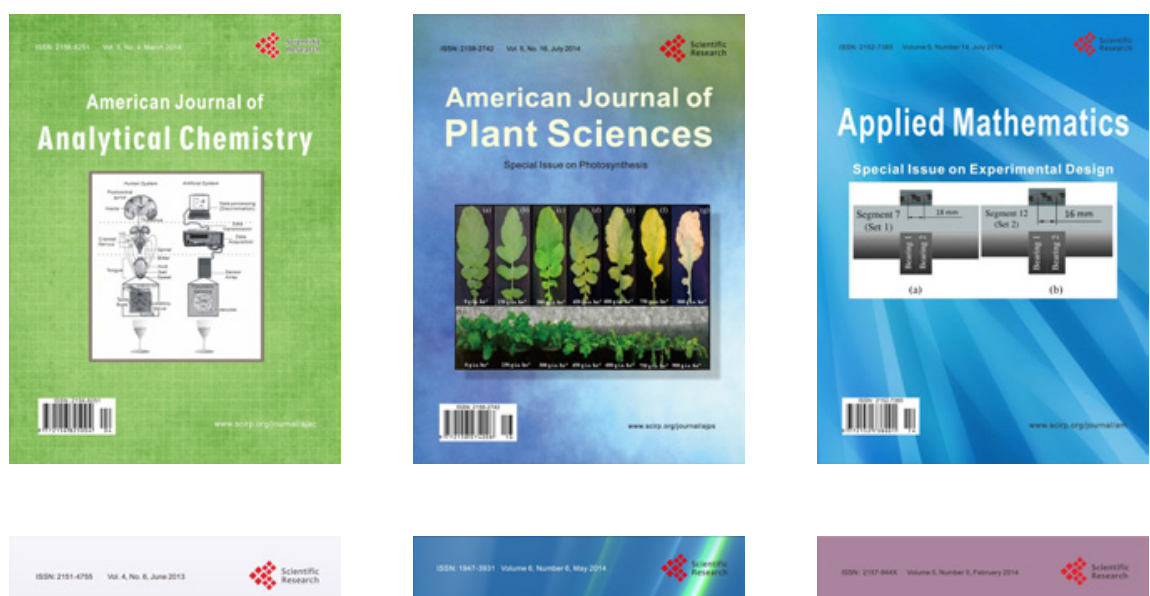

Creative Education
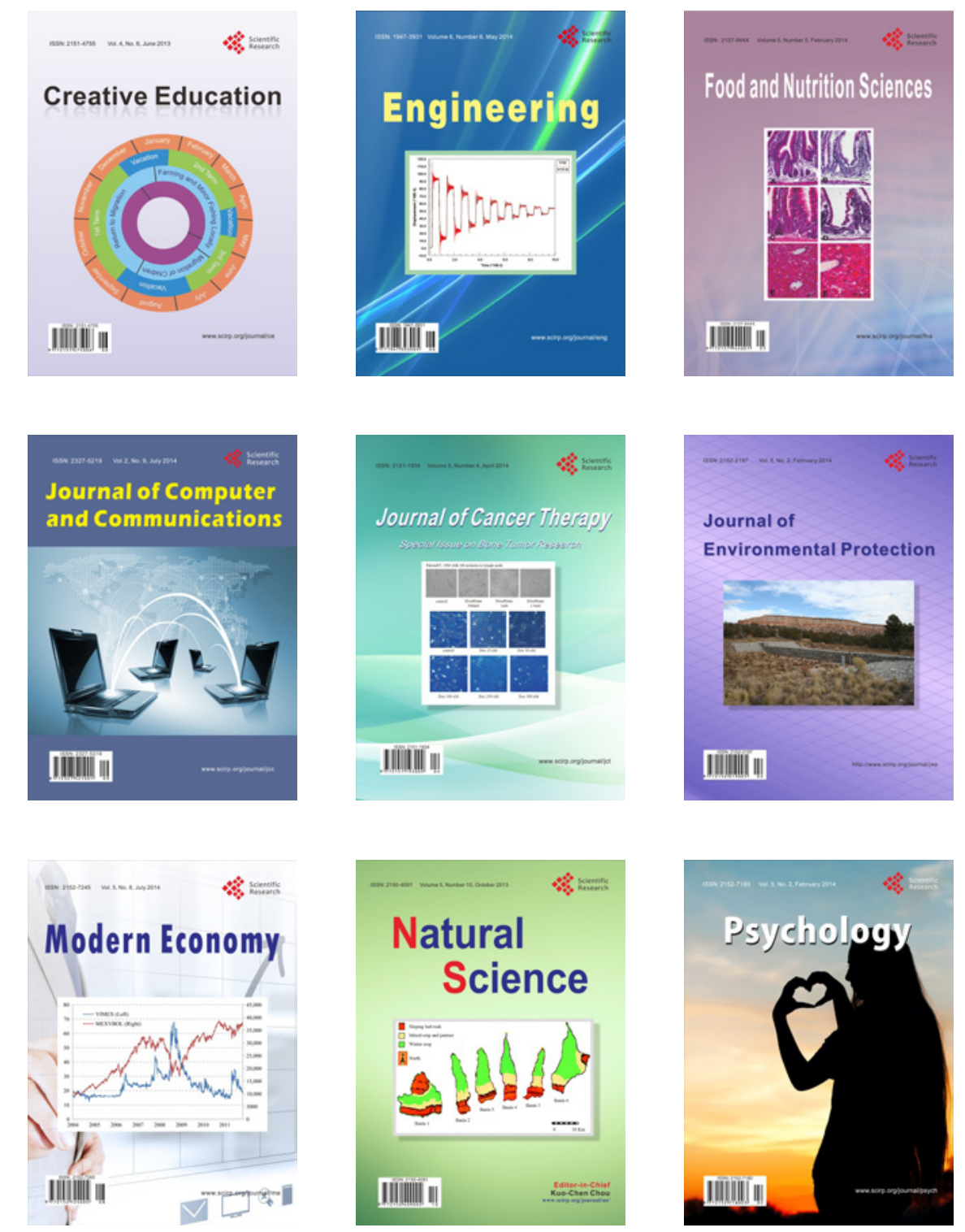